\title{
Cerebral microcirculation is impaired during sepsis: an experimental study
}

\author{
Fabio Silvio Taccone ${ }^{1}$, Fuhong Su${ }^{1}$, Charalampos Pierrakos ${ }^{1}$, Xinrong He ${ }^{1}$, Syril James ${ }^{2}$, Olivier Dewitte ${ }^{2}$, \\ Jean-Louis Vincent ${ }^{1 *}$, Daniel De Backer ${ }^{1}$
}

\begin{abstract}
Introduction: Pathophysiology of brain dysfunction due to sepsis remains poorly understood. Cerebral microcirculatory alterations may play a role; however, experimental data are scarce. This study sought to investigate whether the cerebral microcirculation is altered in a clinically relevant animal model of septic shock.

Methods: Fifteen anesthetized, invasively monitored, and mechanically ventilated female sheep were allocated to a sham procedure $(n=5)$ or sepsis $(n=10)$, in which peritonitis was induced by intra-abdominal injection of autologous faeces. Animals were observed until spontaneous death or for a maximum of 20 hours. In addition to global hemodynamic assessment, the microcirculation of the cerebral cortex was evaluated using Sidestream DarkField (SDF) videomicroscopy at baseline, 6 hours, 12 hours and at shock onset. At least five images of 20 seconds each from separate areas were recorded at each time point and stored under a random number to be analyzed, using a semi-quantitative method, by an investigator blinded to time and condition.

Results: All septic animals developed a hyperdynamic state associated with organ dysfunction and, ultimately, septic shock. In the septic animals, there was a progressive decrease in cerebral total perfused vessel density (from $5.9 \pm 0.9$ at baseline to $4.8 \pm 0.7 \mathrm{n} / \mathrm{mm}$ at shock onset, $P=0.009$ ), functional capillary density (from $2.8 \pm 0.4$ to $2.1 \pm 0.7 \mathrm{n} / \mathrm{mm}, P=0.049$ ), the proportion of small perfused vessels (from $95 \pm 3$ to $85 \pm 8 \%, P=0.02$ ), and the total number of perfused capillaries (from $22.7 \pm 2.7$ to $17.5 \pm 5.2 \mathrm{n} / \mathrm{mm}, P=0.04$ ). There were no significant changes in microcirculatory flow index over time. In sham animals, the cerebral microcirculation was unaltered during the study period.
\end{abstract}

Conclusions: In this model of peritonitis, the cerebral microcirculation was impaired during sepsis, with a significant reduction in perfused small vessels at the onset of septic shock. These alterations may play a role in the pathogenesis of septic encephalopathy.

\section{Introduction}

Sepsis and septic shock still represent major health issues, with persisting high morbidity and mortality rates in critically ill patients [1]. Sepsis is associated with tissue hypoperfusion and metabolic impairment, which may contribute to the associated multiple organ failure [2]. Cerebral dysfunction occurs commonly during severe sepsis, but its pathophysiology remains poorly understood [3]. Inflammation, blood-brain barrier (BBB) abnormalities, impairment of astrocytes and neurons, neurotransmitter derangements and apoptosis may all

\footnotetext{
* Correspondence: jlvincen@ulb.ac.be

'Department of Intensive Care, Erasme Hospital, Université Libre de Bruxelles, Route de Lennik, 808, 1070 - Bruxelles, Belgium

Full list of author information is available at the end of the article
}

be involved [4]; nevertheless, some autopsy reports in patients who died in refractory septic shock described diffuse cerebral ischemic lesions, suggesting that impaired oxygen delivery to the brain could be involved in the development of sepsis-associated encephalopathy (SAE) [5]. As the brain is very dependent on an appropriate blood supply, some studies have suggested that reduced cerebral blood flow (CBF) [6] or disturbed cerebral autoregulation $[7,8]$ may be implicated in the pathogenesis of SAE. However, brain dysfunction during sepsis may occur even when global hemodynamics seem to be adequate [9], and microcirculatory failure may, therefore, play a role in the occurrence of SAE [4].

Microcirculatory perfusion is responsible for the finetuning of the oxygen supply to the organs [10] and 
microcirculatory alterations may play a key role in the pathogenesis of sepsis-related organ dysfunction $[11,12]$. Sepsis-associated microcirculatory alterations include a decrease in capillary density and an increased heterogeneity of blood flow with perfused capillaries in close proximity to stopped or intermittently-perfused capillaries [10]. These alterations have been reported in the sublingual area [13-16], but similar findings have also been described in experimental models of sepsis in many organs, including striated muscle, small bowel mucosa and liver [17-20].

The impact of sepsis on the brain microcirculation is not well defined. Some animal studies described alterations in the cerebral microvascular network during sepsis [21-25] but these studies were limited by several factors. First, the laser Doppler techniques used to assess the microcirculation are unable to discriminate capillary flow from flow in other microvessels $[21,22]$. Second, these studies observed animals for a short period of time thus limiting extrapolation of these results to the entire time course of the septic process. Third, the model used was not always clinically relevant because of the limited amount of fluid resuscitation and the absence of a hyperkinetic phase.

We evaluated the occurrence of microcirculatory alterations during sepsis in a clinically relevant ovine model of sepsis induced by fecal peritonitis. We used the sidestream dark field (SDF) imaging technique, a modified orthogonal polarization spectral (OPS) technology [26], which has been successfully used to study the cerebral microcirculation in experimental models of cardiogenic and hemorrhagic shock $[27,28]$ and cardiac arrest [29]. We hypothesized that the cerebral microcirculation may be impaired during sepsis and that these alterations would be unrelated to the global hemodynamic changes.

\section{Materials and methods}

The study protocol was approved by the Institutional Review Board for Animal Care of the Free University of Brussels, Brussels, Belgium. Care and handling of the animals followed National Institutes of Health guidelines [30].

\section{Experimental animals}

Twelve female sheep, weighing between 27 and $35 \mathrm{~kg}$, were fasted for 24 hours with free access to water prior to the experiment. On the day of the experiment, the animals were premedicated with intramuscular midazolam $(0.25 \mathrm{mg} / \mathrm{kg}$, Dormicum, Roche SA, Beerse, Belgium) and ketamine hydrochloride $(20 \mathrm{mg} / \mathrm{kg}$, Imalgine, Merial, Lyon, France) and then placed in the supine position. The cephalic vein was cannulated with a peripheral venous 18-gauge catheter (Surflo IV Catheter,
Terumo Medical Company, Leuven, Belgium). An intravenous administration of $30 \mu \mathrm{g} / \mathrm{kg}$ fentanyl citrate (Janssen, Beerse, Belgium) and $0.1 \mathrm{mg} / \mathrm{kg}$ rocuronium bromide (Esmeron, Organon, Oss, The Netherlands) was used for endotracheal intubation $(8 \mathrm{~mm}$ endotracheal tube, Hi-Contour, Mallinckrodt Medical, Athlone, Ireland). All sheep were sedated with a continuous intravenous administration of midazolam $\left(0.2 \mathrm{mg} \cdot \mathrm{kg}^{-1}\right.$ $\left.\cdot \mathrm{hr}^{-1}\right)$, ketamine hydrochloride $\left(0.5 \mathrm{mg} \cdot \mathrm{kg}^{-1} \cdot \mathrm{hr}^{-1}\right)$ and morphine $\left(0.2 \mathrm{mg} \cdot \mathrm{kg}^{-1} \cdot \mathrm{hr}^{-1}\right)$. Muscular blockade was achieved using $10 \mu \mathrm{g} \cdot \mathrm{kg}^{-1} \cdot \mathrm{hr}^{-1}$ of rocuronium throughout the experiment to avoid movement artefacts. Boluses of fentanyl $(5 \mathrm{mg})$ were administered if needed in case of tachycardia and/or hypertension suggesting insufficient anesthesia. Mechanical ventilation (Servo $900 \mathrm{C}$ ventilator; Siemens-Elema, Solna, Sweden) was begun with the following settings: tidal volume of $10 \mathrm{~mL} / \mathrm{kg}$, respiratory rate of 12 to 16 breaths/minute, positive end-expiratory pressure of $5 \mathrm{~cm} \mathrm{H}_{2} \mathrm{O}$, an inspired oxygen fraction $\left(\mathrm{FiO}_{2}\right)$ of 1 , inspiratory time to expiratory time ratio of $1: 2$ and a square-wave pattern. Respiratory rate was adjusted to maintain end-tidal carbon dioxide pressure $($ PetCO 2,47210 A Capnometer; Hewlett Packard $\mathrm{GmbH}$, Boehlingen, Germany) between 35 and $45 \mathrm{mmHg}$ before arterial cannulation was established. A $60 \mathrm{~cm}$ plastic tube (inner-diameter $1.8 \mathrm{~cm}$ ) was inserted into the stomach to drain its content and to prevent rumen distension. A 14F Foley catheter (Beiersdorf AG, Hamburg, Germany) was placed to record the urinary output throughout the experiment.

\section{Surgical procedures}

The right femoral artery and vein were surgically exposed. A 6F arterial catheter (Vygon, Cirencester, UK) was invasively introduced into the femoral artery and connected to a pressure transducer (Edwards Lifescience, Irvine, CA, USA) zeroed at mid-chest level. An introducer was inserted through the femoral vein, and a 7F Swan-Ganz catheter (Edwards Lifesciences) was advanced into the pulmonary artery. A midline laparotomy was then performed in 10 animals (sepsis group). After cecotomy, $1.5 \mathrm{~g} / \mathrm{kg}$ body weight of feces was collected. The cecum was then closed and the area around the cut disinfected with iodine solution. An additional suture was performed to prevent contamination and the cecum was returned to the abdominal cavity. A large plastic tube was inserted through the abdominal wall for later injection of feces. The abdomen was then closed in two layers. During the surgical operation, Ringer's lactate and 6\% hydroxyethyl starch (HES) solutions were infused at rates of $1 \mathrm{~mL} \cdot \mathrm{kg}^{-1} \cdot \mathrm{hr}^{-1}$ and $2 \mathrm{~mL} \cdot \mathrm{kg}^{-1} \cdot \mathrm{hr}^{-1}$, respectively. After abdominal surgery, the animals were turned to the prone position and allowed to stabilize before baseline measurements were recorded. Bilateral 
craniotomy was performed in all animals using a highspeed drill and a fine wire saw (Aesculap-Werke AG, Tuttlingen, Germany) to open two holes and connect them until a segment of bone (bone flap) of about $3 \times 3$ $\mathrm{cm}$ was created in the sheep's frontal bone. The dura covering the frontal lobes was then opened in a large incision carefully avoiding any cortical damage. The left and right frontal lobes were exposed and bleeding from the skull was controlled using surgical wax. At the end of the procedure, the skin flaps were sutured in place. The craniotomy holes were then protected by wet sterile gauzes, avoiding any contact with the brain cortex. Brain desiccation was prevented by local hourly administration of $2 \mathrm{~mL}$ saline solution. Five animals, in which all experimental procedures were performed except laparotomy and feces injection, served as sham controls.

\section{Monitoring and measurements}

Volume-controlled mechanical ventilation was adjusted to ensure normoxia ( $80 \mathrm{mmHg} \leq \mathrm{PaO}_{2} \leq 120 \mathrm{mmHg}$ ) and normocapnia (35 $\mathrm{mmHg} \leq \mathrm{PaCO}_{2} \leq 45 \mathrm{mmHg}$ ) according to repeated blood gas analysis (ABL500; Radiometer, Copenhagen, Denmark). Hemoglobin concentration and oxygen saturation were measured with an analyzer calibrated for ruminant animals (OSM3; Radiometer). Peak airway pressure, plateau airway pressure, expiratory gas flow and $\mathrm{FiO}_{2}$ were recorded hourly. Thoracopulmonary compliance was calculated using a standard formula. Arterial samples were obtained at baseline and then hourly after feces spillage. The total amount of blood withdrawn for analyses was around $60 \mathrm{~mL}$ (that is, around three percent of each sheep's estimated total blood volume). All monitored variables were recorded every 60 minutes. Measurements of mean arterial pressure (MAP), pulmonary arterial pressure, right atrial pressure, and pulmonary artery occlusion pressure (PAOP) were obtained at end-expiration (Sirecust 404; Siemens, Erlangen, Germany). Core temperature and cardiac output (Vigilance; Baxter, Edwards Critical Care) were continuously monitored. Body surface area [31], cardiac index, stroke volume index, and systemic vascular resistance (SVR) were calculated using standard formulas.

\section{Cerebral microcirculation}

The microvascular network of the cerebral cortex was visualized using an SDF videomicroscopy system (MicroScan ${ }^{\mathrm{TM}}$, MicroVisionMedical Inc, Amsterdam, Netherlands), with a $5 \times$ imaging objective giving $326 \times$ magnification. The lens of the imaging device was covered with a disposable sterile cap and was applied without pressure to the cerebral frontal cortex. Because of brain pulsatility, this was best accomplished by placing the device on a metallic arm for stabilization (Giesseci, Avellino, Italy). The absence of pressure was ensured by preservation of flow in large vessels [32]. Guided by previous published studies in the same model [33], images were recorded at times 0 (baseline), 6 hours (corresponding to the hyperdynamic phase) and 12 hours (corresponding to the onset of organ dysfunctions). In view of the fact that some animals may die earlier than 18 hours after feces injection and that global hemodynamics in the late phase of sepsis vary from one animal to the other [33], the last time point was considered at shock onset (defined as MAP $<65 \mathrm{mmHg}$ refractory to fluid administration and lactate level $>2.0 \mathrm{mmol} / \mathrm{L}$ ). At least five videostrips from different areas, each of minimum duration of 20 seconds, were recorded on disk, using a computer and a video card (MicroVideo; Pinnacle Systems, Mountain View, CA, USA). The images were then stored under a random number for further analysis. An investigator blinded to group allocation and time later analyzed these sequences semi-quantitatively $[13,32]$. In brief, three equidistant horizontal and three equidistant vertical lines were drawn. The vascular density was calculated as the number of vessels crossing these lines divided by the total length of the lines. The type of flow was defined as continuous, intermittent or absent [32]. To compute the Mean Flow Index (MFI), vessels with continuous flow were further divided into normal and sluggish [34]. Vessel size was determined using a micrometer scale and the vessels were separated into large and small vessels, using a diameter cutoff value of $20 \mu \mathrm{m}$ [32]. Small vessel perfusion was defined as the proportion of small perfused vessels (PSPV), and calculated as the number of capillaries continuously perfused during the 20-second observation period divided by the total number of vessels of the same type. Small perfused vascular density (FCD) was calculated as the product of capillary density and perfused vessel density of vessels of same type. The Heterogeneity Index for both MFI and PSPV [15] was also calculated. In each animal, the data from the investigated areas were averaged for each time point.

\section{Experimental protocol}

After the surgical procedures, baseline measurements, including cerebral microcirculation, were obtained. Feces were then spilled into the abdominal cavity. In feces samples from earlier experiments in this model, the bacterial load was of similar magnitude in all animals (unpublished data). Ringer's lactate and 6\% HES solutions were infused at a rate titrated to avoid hypovolemia and to maintain the PAOP at baseline level. All animals were observed until spontaneous death or for a maximum of 20 hours after the induction of peritonitis. 


\section{Statistical analysis}

Statistical analysis was performed using SPSS 13.0 for Windows (2004; SPSS Inc, Chicago, IL, USA). Data are presented as mean \pm SD or median (range). Variables were compared with parametric Student's $t$-test or the Mann-Whitney U test for nonparametric data. Twoway ANOVA for groups per time interaction and group and time comparisons, with Bonferroni correction for post hoc analysis, was used. Linear correlation was calculated using Spearman correlation coefficient. A $P$-value of $<0.05$ was considered statistically significant.

\section{Results}

There were no differences in baseline global or regional hemodynamic values between the sham and septic animals (Tables 1 and 2). The septic animals developed three distinctive states over time. Three hours after sepsis induction, these animals developed a hyperdynamic state, characterized by an increased cardiac index and relatively preserved MAP without obvious signs of organ dysfunction (Figures 1, 2, 3 and 4). After 11 to 14 hours, the $\mathrm{PaO}_{2} / \mathrm{FiO}_{2}$ ratio and thoracopulmonary compliance decreased, indicating sepsis-related pulmonary dysfunction. Finally, lactic acidosis and refractory hypotension occurred in all animals (15 hours after feces injection in three, after 18 hours in seven animals). The hyperdynamic state persisted until the agonal phase. All animals died after 18 to 20 hours, except two which died after 16 hours. The five sham animals had stable MAP, CI, and pulmonary function throughout the study period (Figures 1, 2, 3 and 4).

Table 1 Evolution of systemic hemodynamics and acid-base variables over time in the septic $(n=10)$ and the sham $(n=5)$ animals

\begin{tabular}{|c|c|c|c|c|c|c|c|}
\hline & & \multirow[t]{2}{*}{ Baseline } & \multirow[t]{2}{*}{6 hours } & \multirow[t]{2}{*}{12 hours } & \multirow[t]{2}{*}{18 hours $^{\#}$} & \multicolumn{2}{|c|}{ ANOVA } \\
\hline & & & & & & Time $(P)$ & Groups $(P)$ \\
\hline \multirow[t]{2}{*}{ Temperature, ${ }^{\circ} \mathrm{C}$} & Sepsis & $39.5 \pm 0.5$ & $39.9 \pm 0.8$ & $40.2 \pm 1.1^{a, b}$ & $41.2 \pm 0.8^{a, b, c *}$ & 0.0002 & 0.01 \\
\hline & Sham & $39.6 \pm 0.3$ & $39.4 \pm 0.5$ & $39.7 \pm 0.7$ & $40.4 \pm 0.5$ & 0.65 & \\
\hline \multirow[t]{2}{*}{ HR, beats/min } & Sepsis & $116 \pm 27$ & $137 \pm 22^{a}$ & $138 \pm 14^{a}$ & $140 \pm 15^{a}$ & 0.05 & 0.38 \\
\hline & Sham & $108 \pm 15$ & $132 \pm 13$ & $132 \pm 14$ & $133 \pm 8^{a}$ & 0.04 & \\
\hline \multirow[t]{2}{*}{ Cardiac Index, L/min.m ${ }^{2}$} & Sepsis & $4.5 \pm 0.5$ & $7.3 \pm 1.3^{\mathrm{a} *}$ & $6.9 \pm 1.5^{\mathrm{a} *}$ & $5.6 \pm 1.3$ & $<0.0001$ & $<0.0001$ \\
\hline & Sham & $4.5 \pm 0.6$ & $5.3 \pm 1.0$ & $5.2 \pm 1.0$ & $5.0 \pm 0.4$ & 0.21 & \\
\hline \multirow[t]{2}{*}{$\mathrm{MAP}, \mathrm{mmHg}$} & Sepsis & $106 \pm 11$ & $101 \pm 11$ & $84 \pm 10^{a} *$ & $56 \pm 6^{a, b *}$ & $<0.0001$ & 0.0002 \\
\hline & Sham & $112 \pm 11$ & $105 \pm 9$ & $107 \pm 10$ & $100 \pm 4$ & 0.32 & \\
\hline \multirow[t]{2}{*}{ MPAP, $\mathrm{mmHg}$} & Sepsis & $15 \pm 4$ & $14 \pm 2$ & $19 \pm 4^{a, b}$ & $20 \pm 4^{a, b}$ & $<0.0001$ & 0.06 \\
\hline & Sham & $16 \pm 1$ & $15 \pm 3$ & $16 \pm 3$ & $17 \pm 5$ & 0.86 & \\
\hline \multirow[t]{2}{*}{ SVRI, dynes.sec.cm ${ }^{-5}$} & Sepsis & $1853 \pm 211$ & $1120 \pm 248^{a}$ & $960 \pm 211^{a *}$ & $777 \pm 176^{a, b *}$ & $<0.0001$ & $<0.0001$ \\
\hline & Sham & $1907 \pm 253$ & $1540 \pm 292$ & $1597 \pm 273$ & $1691 \pm 138$ & 0.1 & \\
\hline \multirow[t]{2}{*}{ PF ratio } & Sepsis & $302 \pm 110$ & $326 \pm 113$ & $283 \pm 96 *$ & $197 \pm 91^{b *}$ & 0.01 & $<0.0001$ \\
\hline & Sham & $392 \pm 68$ & $407 \pm 40$ & $377 \pm 24$ & $379 \pm 29$ & 0.69 & \\
\hline \multirow[t]{2}{*}{$\mathrm{PaCO}_{2}, \mathrm{mmHg}$} & Sepsis & $41 \pm 3$ & $39 \pm 2$ & $41 \pm 4$ & $46 \pm 9^{b}$ & 0.009 & 0.11 \\
\hline & Sham & $37 \pm 3$ & $39 \pm 3$ & $39 \pm 4$ & $42 \pm 4$ & 0.09 & \\
\hline \multirow[t]{2}{*}{$\mathrm{TPC}, \mathrm{mL} / \mathrm{mmHg}$} & Sepsis & $18 \pm 2$ & $19 \pm 4$ & $15 \pm 4$ & $12 \pm 3^{a, b}$ & 0.0002 & 0.23 \\
\hline & Sham & $18 \pm 3$ & $18 \pm 1$ & $17 \pm 2$ & $15 \pm 3$ & 0.22 & \\
\hline \multirow[t]{2}{*}{ Urine output, $\mathrm{mL} / \mathrm{hr}$} & Sepsis & $96 \pm 36$ & $105 \pm 100$ & $99 \pm 85$ & $127 \pm 65$ & 0.53 & 0.053 \\
\hline & Sham & $79 \pm 25$ & $128 \pm 45$ & $155 \pm 99$ & $95 \pm 35$ & 0.48 & \\
\hline \multirow[t]{2}{*}{ Fluid amount, $\mathrm{mL}$} & Sepsis & $314 \pm 110$ & $1635 \pm 596^{a} *$ & $1705 \pm 497^{a} *$ & $2210 \pm 854^{a, b, c} *$ & $<0.0001$ & $<0.0001$ \\
\hline & Sham & $218 \pm 65$ & $265 \pm 93$ & $310 \pm 74$ & $278 \pm 61$ & 0.81 & \\
\hline \multirow[t]{2}{*}{ Hemoglobin, g/dL } & Sepsis & $10.7 \pm 1.1$ & $10.9 \pm 1.6$ & $11.1 \pm 1.2$ & $11.6 \pm 1.6$ & 0.56 & 0.66 \\
\hline & Sham & $10.5 \pm 0.7$ & $10.5 \pm 0.8$ & $11.3 \pm 0.7$ & $11.4 \pm 0.7$ & 0.49 & \\
\hline \multirow[t]{2}{*}{ Lactate $(\mathrm{mEq} / \mathrm{L})$} & Sepsis & $0.9 \pm 0.3$ & $1.3 \pm 0.5$ & $1.7 \pm 0.7^{a} *$ & $4.0 \pm 1.2^{a, b, c *}$ & $<0.0001$ & $<0.0001$ \\
\hline & Sham & $0.7 \pm 0.2$ & $0.6 \pm 0.3$ & $0.7 \pm 0.2$ & $0.8 \pm 0.4$ & 0.71 & \\
\hline
\end{tabular}

Data are presented as mean \pm SD.

\# Shock onset for septic group.

${ }^{\circ} \mathrm{C}$, Celsius degrees; HR, heart rate; $\mathrm{Cl}$, cardiac index; MAP, mean arterial pressure; MPAP, mean pulmonary arterial pressure; SVRI, systemic vascular resistance index; $\mathrm{PF}, \mathrm{PaO} 2 / \mathrm{FiO} 2 ; \mathrm{TPC}$, thoraco-pulmonary compliance.

No interference between time and groups was found for all the studied variables in ANOVA analysis. Significant at $5 \%$ vs. baseline $\left({ }^{\mathrm{a}}\right)$, vs 6 hours $\left({ }^{\mathrm{b}}\right)$ or vs 12 hours $\left({ }^{C}\right)$ or significant at $5 \%$ vs. sham $\left(^{*}\right)$ in post-hoc Bonferroni correction. 
Table 2 Evolution in cerebral microcirculation over time in the septic $(n=10)$ and the sham $(n=5)$ animals

\begin{tabular}{|c|c|c|c|c|c|c|c|}
\hline & & \multirow[t]{2}{*}{ Baseline } & \multirow[t]{2}{*}{6 hours } & \multirow[t]{2}{*}{12 hours } & \multirow[t]{2}{*}{18 hours $^{\#}$} & \multicolumn{2}{|c|}{ ANOVA } \\
\hline & & & & & & Time $(P)$ & Groups $(P)$ \\
\hline \multirow[t]{2}{*}{ TVD } & Sepsis & $6.1 \pm 0.8$ & $5.4 \pm 0.5$ & $5.7 \pm 0.8$ & $5.4 \pm 0.6$ & 0.15 & 0.61 \\
\hline & Sham & $5.8 \pm 0.8$ & $5.9 \pm 0.7$ & $5.6 \pm 0.8$ & $5.8 \pm 0.6$ & 0.65 & \\
\hline \multirow[t]{2}{*}{ TPVD } & Sepsis & $5.9 \pm 0.9$ & $5.1 \pm 0.5$ & $5.1 \pm 0.6$ & $4.8 \pm 0.7^{\mathrm{a}}$ & 0.009 & 0.14 \\
\hline & Sham & $5.7 \pm 0.7$ & $5.8 \pm 0.7$ & $5.5 \pm 0.7$ & $5.5 \pm 0.5$ & 0.76 & \\
\hline \multirow[t]{2}{*}{ NPC } & Sepsis & $22.7 \pm 2.8$ & $18.8 \pm 3.2 *$ & $18.7 \pm 5.9 *$ & $17.5 \pm 5.2 * a$ & 0.048 & $<0.001$ \\
\hline & Sham & $25.1 \pm 0.9$ & $24.7 \pm 2.3$ & $23.8 \pm 3.3$ & $25.8 \pm 0.8$ & 0.42 & \\
\hline \multirow[t]{2}{*}{ MFI } & Sepsis & $2.9 \pm 0.1$ & $2.9 \pm 0.1$ & $2.9 \pm 0.1$ & $2.7 \pm 0.3$ & 0.21 & 0.87 \\
\hline & Sham & $2.9 \pm 0.1$ & $2.9 \pm 0.1$ & $2.9 \pm 0.1$ & $2.8 \pm 0.2$ & 0.33 & \\
\hline \multirow[t]{2}{*}{ PSPV - HI } & Sepsis & $0.11 \pm 0.06 *$ & $0.26 \pm 0.15 * a$ & $0.23 \pm 0.11 *$ & $0.32 \pm 0.13$ *a & 0.002 & $<0.001$ \\
\hline & Sham & $0.04 \pm 0.01$ & $0.03 \pm 0.01$ & $0.03 \pm 0.02$ & $0.06 \pm 0.04$ & 0.25 & \\
\hline \multirow[t]{2}{*}{$\mathrm{MFI}-\mathrm{HI}$} & Sepsis & $0.13 \pm 0.07$ & $0.18 \pm 0.13$ & $0.23 \pm 0.14 * a$ & $0.25 \pm 0.14$ *a & 0.003 & 0.002 \\
\hline & Sham & $0.07 \pm 0.06$ & $0.18 \pm 0.09$ & $0.08 \pm 0.05$ & $0.13 \pm 0.07$ & 0.19 & \\
\hline
\end{tabular}

Data are presented as mean \pm SD.

\# Shock onset for septic group.

Significant at $5 \%$ vs. baseline $\left({ }^{\mathrm{a}}\right)$, vs 6 hours $\left({ }^{\mathrm{b}}\right)$ or vs 12 hours $\left({ }^{\mathrm{c}}\right)$. Significant at $5 \%$ vs. sham $\left({ }^{*}\right)$.

TVD, total vessel density; TPVD, total perfused vessel density; PSPV, proportion of small perfused vessels; FCD, functional capillary density; NPC, number of perfused capillaries; $\mathrm{MFI}$, mean flow index; $\mathrm{HI}$, heterogeneity index; $(P)=P$-value.

No interference between time and groups was found for all the studied variables in ANOVA analysis. Significant at $5 \%$ vs. baseline $\left({ }^{a}\right)$, or vs. sham $\left({ }^{*}\right)$ in post-hoc Bonferroni correction.

Changes in cerebral microcirculation at different time points are shown in Table 2 and Figures 5 and 6. Typical images of sheep cerebral microcirculation at baseline and at shock onset are shown in Figures 7 and 8. The development of septic shock was associated with decreases in cerebral total PVD (from $5.9 \pm 0.9$ to $4.8 \pm$ $0.7 \mathrm{n} / \mathrm{mm}, P=0.009$ ), FCD (from $2.8 \pm 0.4$ to $2.1 \pm 0.7$ $\mathrm{n} / \mathrm{mm}, P=0.049$ ), PSPV (from $95 \pm 3$ to $85 \pm 8 \%, P=$ 0.02 ) (Figure 3 ) and the total number of perfused capillaries (from $22.7 \pm 2.7$ to $17.5 \pm 5.2 \mathrm{n} / \mathrm{mm}, P=0.04$ ). PSPV was already decreased at 12 hours (to $85 \pm 6 \%$, $P=0.02$ vs. baseline). There were no significant changes

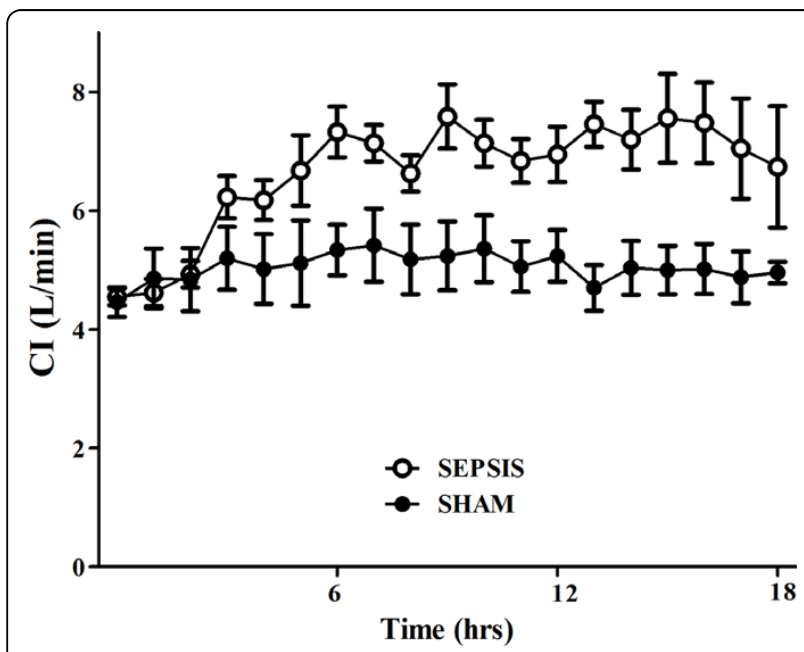

Figure 1 Evolution over time of cardiac index (CI) in sham ( $n=$ 5) and septic $(n=10)$ animals. in total vessel density (TVD) or MFI during the experiment. The heterogeneity index of both MFI and PSPV increased over time (Table 2). The decrease in FCD was not correlated to the changes in CI, MAP or arterial lactate levels (Figure 9). In sham animals, the cerebral microcirculation was unaltered over the study period.

\section{Discussion}

The key finding in this study is that the cortical cerebral microcirculation is altered in this hyperdynamic model of sepsis. These microcirculatory abnormalities became significant at the onset of septic shock, and were not

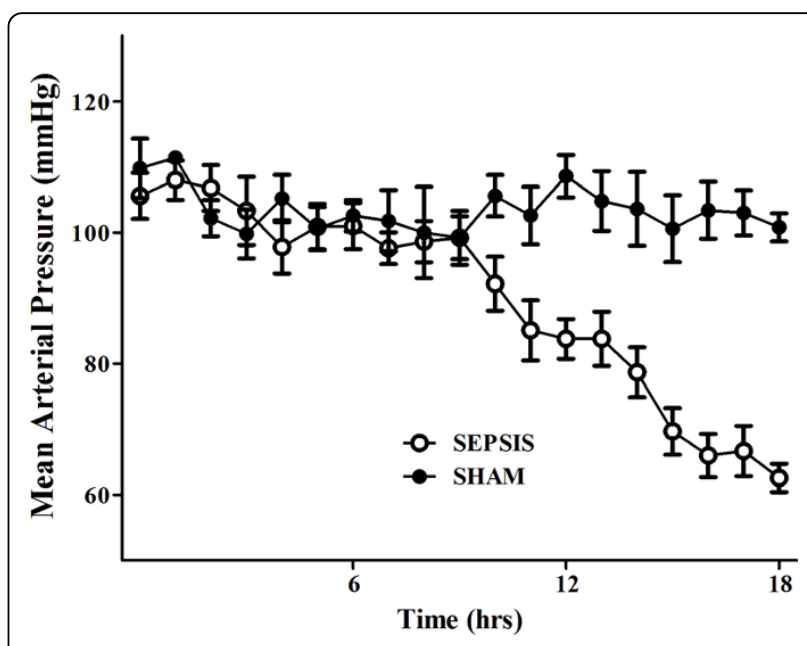

Figure 2 Evolution over time of mean arterial pressure (MAP) in sham $(n=5)$ and septic $(n=10)$ animals. 


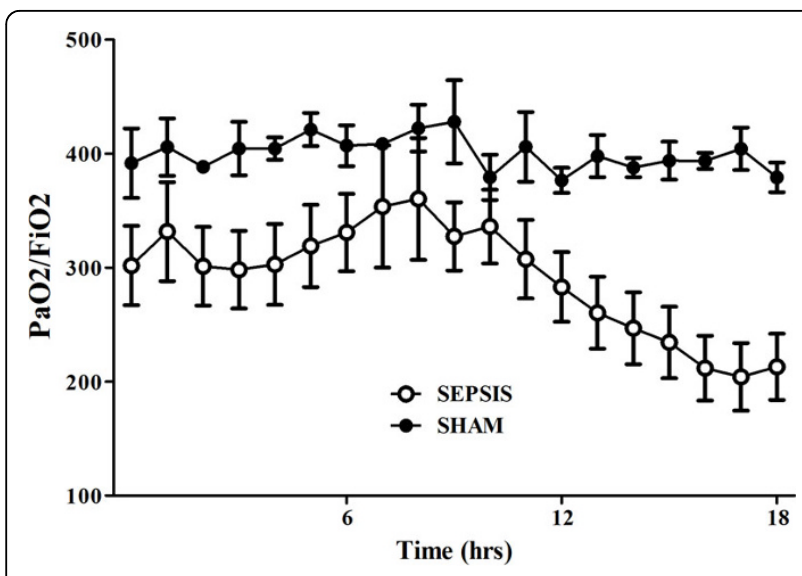

Figure 3 Evolution over time of $\mathrm{PaO} 2 / \mathrm{FiO} 2$ ratio in sham $(n=$ $5)$ and septic $(n=10)$ animals.

prevented by aggressive fluid administration. Interestingly, the variability of FCD and PSPV in septic animals was greater than the variability in sham animals already at six hours after sepsis induction, suggesting that alterations in cerebral microcirculation occur earlier than shown only by the analysis of individual variations. Moreover, changes in the cerebral microcirculation were not related to changes in MAP, CI or lactate, suggesting that these alterations in the brain may occur even when global perfusion pressure is maintained, such as in nonhypotensive conditions.

These findings provide additional evidence of a dissociation between macro- and microcirculations, as reported for the sublingual area in human sepsis [13,32] and suggest that, even after restoration of adequate global hemodynamics, cerebral perfusion may still remain markedly impaired as a result of microcirculatory

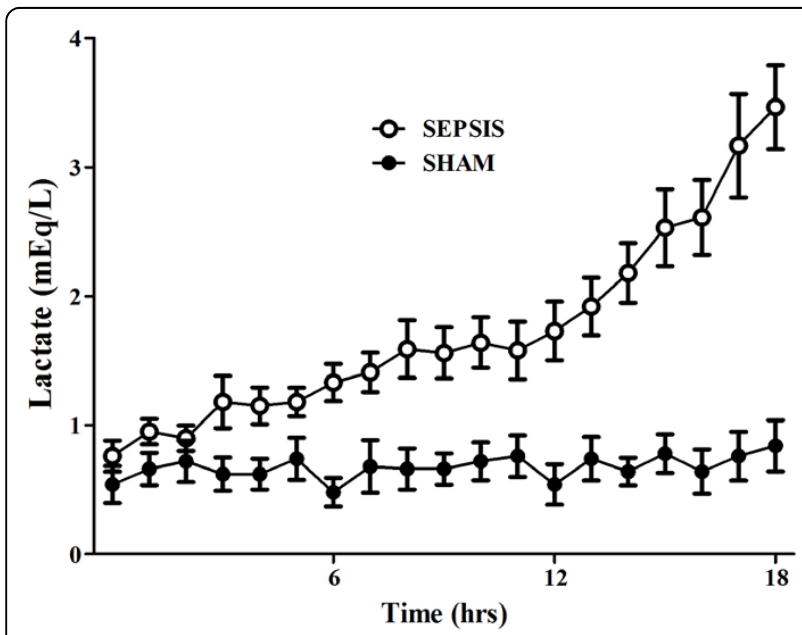

Figure 4 Evolution over time of lactate levels in sham $(n=5)$ and septic $(n=10)$ animals.

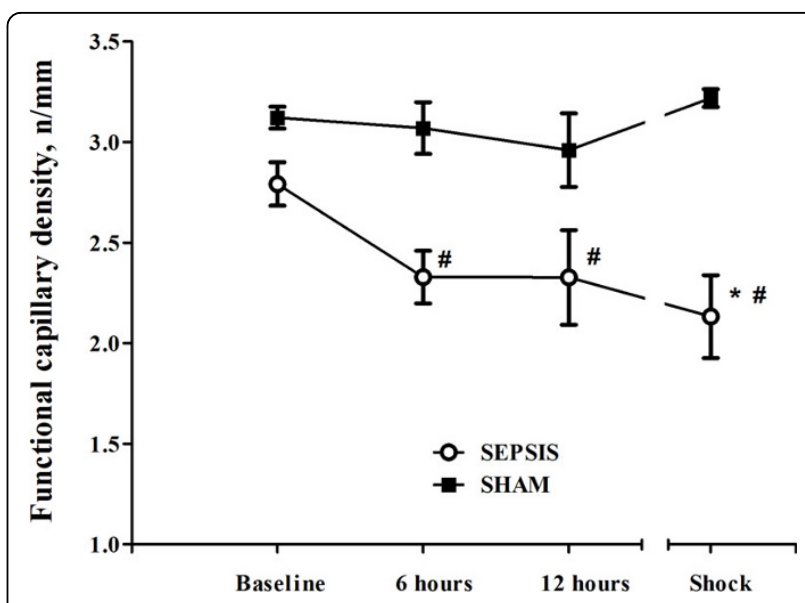

Figure 5 Changes in cerebral functional capillary density (FCD) in the septic $(n=10)$ and the sham $(n=5)$ animals. Data are presented as mean \pm SD. ANOVA analysis for FCD: $P=0.049$ (time, sepsis group) and $P<0.001$ (group). ANOVA analysis for PSPV: $P=$ 0.02 (time, sepsis group) and $P<0.001$ (group). $P$-value $<.05$ vs. baseline $\left(^{*}\right)$ or vs. sham $\left(^{*}\right)$ in post-hoc Bonferroni correction.

alterations. Even though these data can hardly be confirmed in humans, as a craniotomy would be necessary to investigate the cerebral microcirculation in septic patients, their clinical relevance is important, as cerebral microcirculatory disturbances occur early during the septic process and become even more severe at the moment of shock onset. Further studies are needed to investigate whether cerebral microcirculatory changes are influenced by acute modifications in global hemodynamics during sepsis, such as an increase in MAP or cardiac output using adrenergic agents.

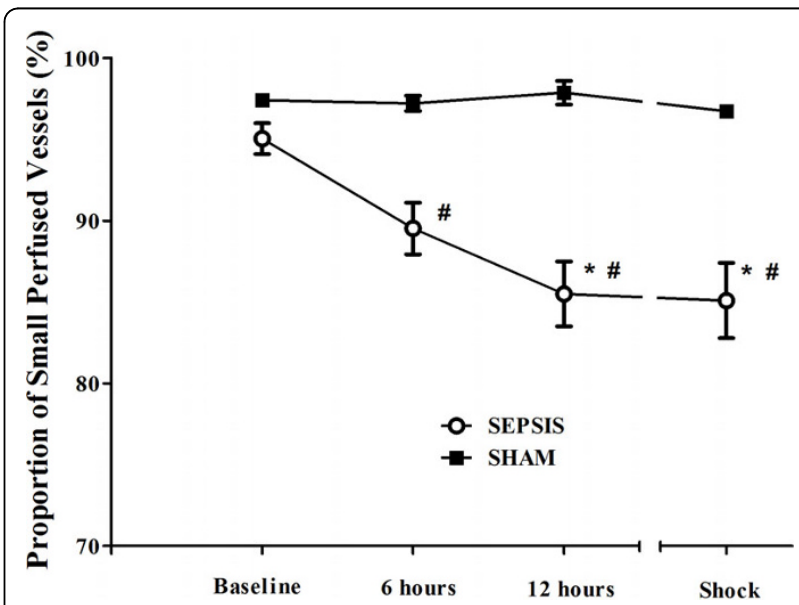

Figure 6 Changes in proportion of small perfused vessels (PSPV) in the septic $(n=10)$ and the sham $(n=5)$ animals. Data are presented as mean \pm SD. ANOVA analysis for FCD: $P=$ 0.049 (time, sepsis group) and $P<0.001$ (group). ANOVA analysis for PSPV: $P=0.02$ (time, sepsis group) and $P<0.001$ (group). $P$-value $<.05$ vs. baseline $\left(^{*}\right)$ or vs. sham $\left(^{*}\right)$ in post-hoc Bonferroni correction. 


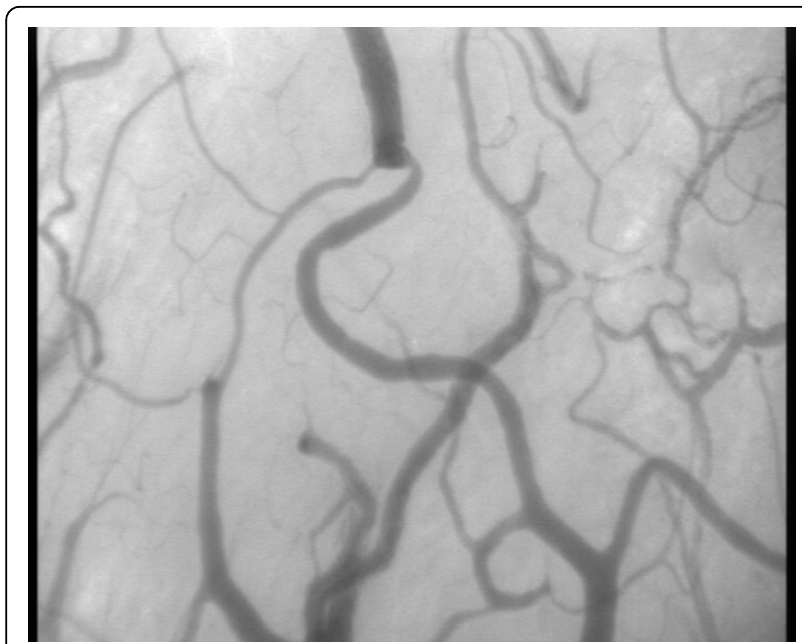

Figure 7 Digital photomicrographs of the cerebral cortical microcirculation of a septic animal at baseline.

What are the mechanisms associated with these alterations? Microvascular perfusion is regulated by an intricate interplay of many neuroendocrine, paracrine and mechano-sensory pathways [35], adapting to the balance between local oxygen delivery and metabolic needs. Thus, one may imagine that mechanisms implicated in microvascular dysfunction in other organs may also be involved in brain microvascular dysfunction. The recruitment of adherent leukocytes into the microcirculation is a determinant feature of the inflammatory response in different tissues [36,37]. Using intravital microscopy in obese rats, Vachharajani et al. showed that cerebral venules presented marked adhesion of platelets and leukocytes to the vascular endothelium already four hours after induced peritonitis, with greatly

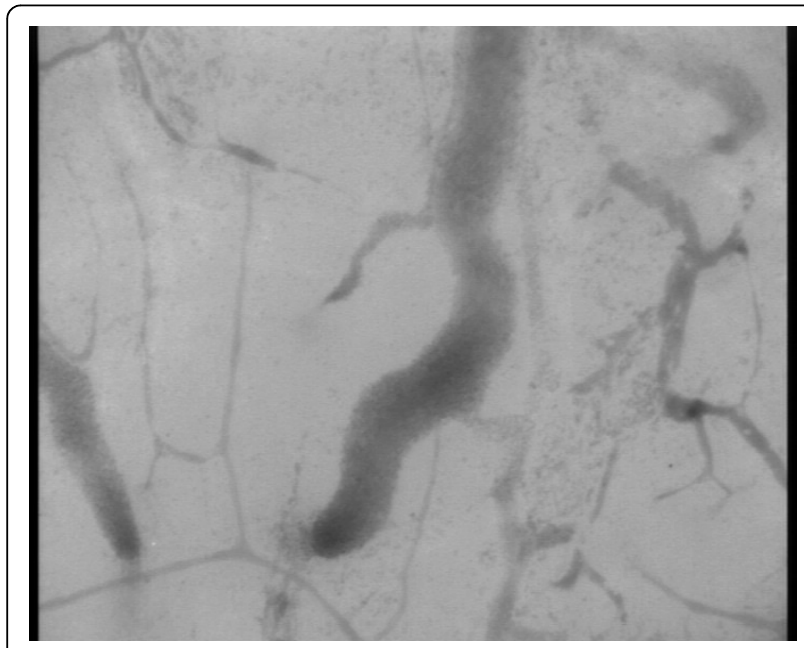

Figure 8 Digital photomicrographs of the cerebral cortical microcirculation of a septic animal at shock onset. exaggerated responses in obese mice compared to the lean animals [23]. These endothelial responses were attenuated by selectively blocking adhesion molecules, such as P-selectin, CD18, or intercellular adhesion molecule (ICAM)-1, or by giving dexamethasone [25] or hypertonic solutions [24]. The changes in microvascular density could also be explained by the increased release of nitric oxide (NO) during sepsis [38]. Interestingly, administration of inhibitors of inducible NO synthase (iNOS) prevented cerebral hyperemia [39] but not brain microvascular alterations [22], suggesting that other mechanisms are involved. On the other hand, in cardiogenic and in hemorrhagic shock, the cerebral microcirculation can be preserved even when peripheral microvascular disturbances are present $[27,28]$. However, the pathophysiology of microcirculatory dysfunction in sepsis may be different and more complex than in these conditions $[40,41]$, and this could explain the cerebral microvascular impairment observed in our study.

What are the consequences of these microvascular alterations? As animals were sedated during the entire experiment and eventually developed fatal sepsis, we were unable to associate microvascular disturbances with clinical neurological abnormalities. Nevertheless, indirect data suggest these alterations may have important consequences on brain cells and function. In endotoxic animals, microcirculatory failure occurred in the early phase of sepsis, and preceded changes in evoked potential responses, indicating that altered perfusion of active neurons is responsible for electrophysiological abnormalities in septic animals [21]. Moreover, cerebral microcirculatory endothelial cells seem to be important structures of the vasoregulative brain system [42], which physiologically maintains a constant $\mathrm{CBF}$ during changes in cerebral perfusion pressure [43]. Cerebral autoregulation may be impaired in septic conditions, not only because severe hypotension has been associated with the occurrence of septic encephalopathy [44], but primarily because failure of the CBF to be regulated by changes in MAP or carbon dioxide has already been documented in experimental and human sepsis $[7,8,45]$. In addition, the septic brain may be more sensitive than other organs to changes in systemic perfusion variables. In septic patients, Berré et al. demonstrated that changes in cardiac output induced by dobutamine or prostacyclin were associated with changes in CBF $[46,47]$. If the microcirculation were also sensitive to or dependent on global hemodynamic changes, then capillary perfusion would have been impaired by a reduction in MAP or improved by an increase in cardiac output. Our results suggest that cerebral autoregulation may be preserved in our septic model, but also that microcirculatory abnormalities in the brain cortex could occur 


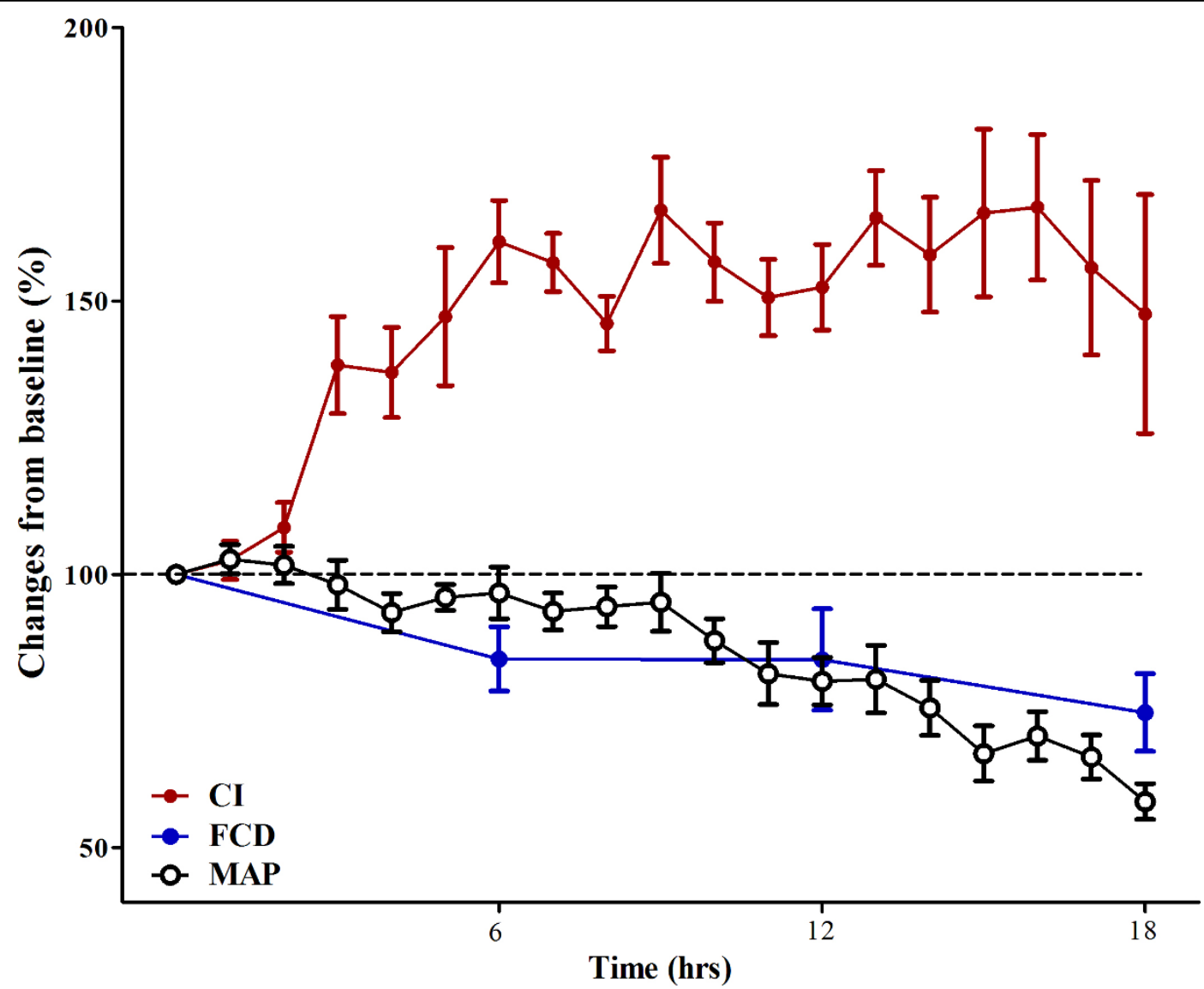

Figure 9 Correlation between microcirculation and global hemodynamics. Changes from baseline (100\%) of cardiac index (Cl; red circles), mean arterial pressure (MAP; white circles) and functional capillary density (FCD; blue circles) over the study period. Changes in FCD appear to occur earlier than significant changes in MAP and already during the hyperdynamic phase.

independently from autoregulatory failure, as has already been reported in another experimental study [48]. Finally, microcirculatory alterations may be implicated in the development of cerebral edema. Edema formation has been observed at autopsy in the cortical regions [49] and in the peri-microvascular area, especially in ganglial cells and hippocampal areas, in various experimental models of sepsis [50-52]. However, brain vasogenic edema, caused by a breakdown in the BBB was not observed in the early phase of sepsis in endotoxic rats using magnetic resonance imaging (MRI), despite the presence of microcirculatory disturbances in those animals [53], suggesting that brain edema occurs later and may be a consequence, rather than a cause, of cerebral microcirculatory disturbances.

There are some limitations to this study. First, it was conducted in previously healthy animals under highly controlled conditions, in contrast to the clinical setting in which patients often have underlying illness and comorbidities, sometimes involving the brain. Second, we did not use antibiotics and vasopressors in order to avoid any influence of these agents on the cerebral microcirculation, although these drugs are currently given in human septic shock. Third, the surgery or the anesthesia provided may have played a role in the observed changes. The absence of microvascular alterations in the sham animals suggests that these procedures were not primarily responsible for these alterations, but they may still have exacerbated the sepsis-induced abnormalities. Moreover, as anesthesia decreases brain metabolism, we may expect an even greater imbalance between microvascular supply and tissue needs in the absence of anesthesia. Fourth, we performed a large bilateral craniectomy that prevented any potential increase in intracranial pressure. However, severe brain swelling has not been reported in several animal and human studies using magnetic resonance imaging (MRI) to study the brain parenchyma during sepsis [53]. Importantly, we avoided local brain injury, minimizing the number of manipulations to four 
different time points, and taking care to avoid tissue desiccation by local administration of saline solution. Fifth, we visualized only pial vessels and the frontal cortex, and these areas may not be representative of deeper brain structures, including white matter and the brain stem; the velocity of red blood cells in the microvessels was not analyzed. On the other hand, the sheep's brain is also relatively similar to the human brain except for its smaller size and anatomical orientation [54]. Despite the presence of a rete mirabilis, the capillary system is similar to the human system and the brain microcirculation images we obtained are quite similar to those shown in the human brain during neurosurgery for subarachnoid hemorrhage [55]. Sixth, we did not measure regional CBF, flow autoregulation or cellular function, and our findings cannot be correlated with cerebral perfusion or metabolism. Moreover, we did not perform any post-mortem histological examination of brain parenchyma. Finally, we could not simultaneously investigate other microcirculations; because of the positioning of the head of the animal (the head was kept in the same position to allow analysis of the same brain region) we could not access the sublingual area. Accordingly, we were unable to evaluate whether these alterations occurred simultaneously with those of other tissues and were of similar severity.

\section{Conclusions}

In this experimental septic shock model, the cerebral microcirculation is impaired, with a significant reduction in perfused small vessels when refractory hypotension and septic shock occur. These alterations may play a role in the pathogenesis of SAE.

\section{Key messages}

- Cerebral microcirculation is progressively impaired during sepsis, with a significant reduction in functional capillary density and proportion of perfused capillaries at shock onset.

- Total vessel density and MFI remain unchanged during the septic process.

- Cerebral microvascular alterations are independent from systemic hemodynamics.

\footnotetext{
Abbreviations

ANOVA: analysis of variance; BBB: brain-blood barrier; CBF: cerebral blood flow; Cl: cardiac index; FCD: functional capillary density; FIO2: inspired fraction of oxygen; HES: hydroxyethyl starch; ICAM: intercellular adhesion molecule; INOS: inducible nitric oxide synthase; MAP: mean arterial pressure; MFI: mean flow index; MRI: magnetic resonance imaging; NPC: number of perfused capillaries; NO: nitric oxide; OPS: orthogonal polarization spectral; PACO2: arterial pressure of carbon dioxide; PAO2: arterial pressure of oxygen; PAOP: pulmonary artery occlusion pressure; PETCO2: end-tidal carbon dioxide pressure; PSPV: proportion of small perfused vessels; PVD: perfused vessels density; SAE: sepsis-associated encephalopathy; SDF: sidestream dark field; SVR: systemic vascular resistance; TVD: total vessel density.
}

\section{Acknowledgements}

We thank Isabelle De Neve, Department of Sterilization at Erasme Hospital, Brussels, Belgium, for the neurosurgical material. We also thank the technicians of the Department of Intensive Care of Erasme Hospital for their technical assistance.

The study was supported by grants from Fondation Erasme, Bruxelles, Belgium (Bourse de Recherche 2008-2009).

\section{Author details}

${ }^{1}$ Department of Intensive Care, Erasme Hospital, Université Libre de Bruxelles, Route de Lennik, 808, 1070 - Bruxelles, Belgium. ²Department of Neurosurgery, Erasme Hospital, Université Libre de Bruxelles, Route de Lennik, 808, 1070 - Bruxelles, Belgium.

\section{Authors' contributions}

FST, FS, JLV and DDB conceived the study protocol. FST, FS, CP, HX, SJ and OD developed the animal model for brain microcirculation analysis. FST, FS, JLV and DDB drafted the present manuscript. All authors read and approved the final manuscript.

\section{Competing interests}

The authors declare that they have no competing interests.

Received: 13 April 2010 Revised: 8 June 2010 Accepted: 28 July 2010 Published: 28 July 2010

\section{References}

1. Vincent $J$, Sakr Y, Sprung CL, Gerlach H, Ranieri VM: Sepsis in European intensive care units: results of the SOAP study. Crit Care Med 2006, 34:344-353.

2. Singh S, Evans TW: Organ dysfunction during sepsis. Intensive Care Med 2006, 32:349-360.

3. Papadopoulos MC, Davies DC, Moss RF, Tighe D, Bennett ED: Pathophysiology of septic encephalopathy: a review. Crit Care Med 2000, 28:3019-3024.

4. Ebersoldt M, Sharshar T, Annane D: Sepsis-associated delirium. Intensive Care Med 2007, 33:941-950.

5. Sharshar T, Gray F, Poron F, Raphael JC, Gajdos P, Annane D: Multifocal necrotizing leukoencephalopathy in septic shock. Crit Care Med 2002, 30:2371-2375.

6. Burkhardt CS, Siegemund M, Steiner LA: Cerebral perfusion in sepsis. Crit Care 2010, 14:215.

7. Pfister D, Siegemund M, Dell-Kuster S, Smielewski P, Rüegg S, Strebel SP, Marsch SC, Pargger H, Steiner LA: Cerebral perfusion in sepsis-associated delirium. Crit Care 2008, 12:R63.

8. Taccone FS, Castanares-Zapatero D, Peres-Bota D, Vincent JL, Berré J, Melot C: Cerebral autoregulation is influenced by carbon dioxide levels in patients with septic shock. Neurocrit Care 2010, 12:35-42.

9. Young GB, Bolton CF, Archibald YM, Austin TW, Wells GA: The electroencephalogram in sepsis-associated encephalopathy. J Clin Neurophysiol 1992, 9:145-152.

10. Ince C: Microcirculation in distress: a new resuscitation end point? Crit Care Med 2004, 32:1963-1964.

11. Bateman RM, Walley KR: Microvascular resuscitation as a therapeutic goal in severe sepsis. Crit Care 2005, 9(Suppl 4):S27-S32.

12. Trzeciak S, McCoy JV, Phillip DR, Arnold RC, Rizzuto M, Abate NL, Shapiro NI, Parrillo JE, Hollenberg SM: Early increases in microcirculatory perfusion during protocol-directed resuscitation are associated with reduced multi-organ failure at $24 \mathrm{~h}$ in patients with sepsis. Intensive Care Med 2008, 34:2210-2217.

13. De Backer D, Creteur J, Preiser JC, Dubois MJ, Vincent JL: Microvascular blood flow is altered in patients with sepsis. Am J Respir Crit Care Med 2002, 166:98-104.

14. Sakr Y, Dubois MJ, De Backer D, Creteur J, Vincent JL: Persistent microcirculatory alterations are associated with organ failure and death in patients with septic shock. Crit Care Med 2004, 32:1825-1831.

15. Trzeciak S, Dellinger RP, Parrillo JE, Guglielmi M, Bajaj J, Abate NL, Arnold RC, Colilla S, Zanotti S, Hollenberg SM: Early microcirculatory perfusion derangements in patients with severe sepsis and septic shock: relationship to hemodynamics, oxygen transport, and survival. Ann Emerg Med 2007, 49:88-98. 
16. Spronk PE, Zandstra DF, Ince C: Bench-to-bedside review: sepsis is a disease of the microcirculation. Crit Care 2004, 8:462-468.

17. Lendemans S, Peszko A, Oberbeck R, Schmitz D, Husain B, Burkhard M, Schade FU, Flohe S: Microcirculatory alterations of hepatic and mesenteric microcirculation in endotoxin tolerance. Shock 2008, 29:223-231.

18. Piper RD, Pitt-Hyde M, Li F, Sibbald WJ, Potter RF: Microcirculatory changes in rat skeletal muscle in sepsis. Am J Respir Crit Care Med 1996, 154:931-937.

19. Farquhar I, Martin CM, Lam C, Potter R, Ellis CG, Sibbald WJ: Decreased capillary density in vivo in bowel mucosa of rats with normotensive sepsis. J Surg Res 1996, 61:190-196.

20. Verdant $C L$, De Backer D, Bruhn A, Clausi CM, Su F, Wang Z, Rodriguez $H$, Pries $A R$, Vincent JL: Evaluation of sublingual and gut mucosal microcirculation in sepsis: a quantitative analysis. Crit Care Med 2009, 37:2875-2881

21. Rosengarten B, Hecht M, Auch D, Ghofrani HA, Schermuly RT, Grimminger F, Kaps M: Microcirculatory dysfunction in the brain precedes changes in evoked potentials in endotoxin-induced sepsis syndrome in rats. Cerebrovasc Dis 2007, 23:140-147.

22. Rosengarten B, Wolff $S$, Klatt $S$, Schermuly RT: Effects of inducible nitric oxide synthase inhibition or norepinephrine on the neurovascular coupling in an endotoxic rat shock model. Crit Care 2009, 13:R139.

23. Vachharajani V, Russell JM, Scott KL, Conrad S, Stokes KY, Tallam L, Hall J, Granger DN: Obesity exacerbates sepsis-induced inflammation and microvascular dysfunction in mouse brain. Microcirculation 2005, 12:183-194.

24. Vachharajani V, Vital S, Russell J, Granger DN: Hypertonic saline and the cerebral microcirculation in obese septic mice. Microcirculation 2007, 14:223-231.

25. Vachharajani V, Vital S, Russell J, Scott LK, Granger DN: Glucocorticoids inhibit the cerebral microvascular dysfunction associated with sepsis in obese mice. Microcirculation 2006, 13:477-487.

26. Lindert J, Werner J, Redlin M, Kuppe $H$, Habazettl $H$, Pries AR: OPS imaging of human microcirculation: a short technical report. J Vasc Res 2002, 39:368-372.

27. Wan Z, Ristagno G, Sun S, Li Y, Weil MH, Tang W: Preserved cerebral microcirculation during cardiogenic shock. Crit Care Med 2009, 37:2333-2337.

28. Wan Z, Sun S, Ristagno G, Weil MH, Tang W: The cerebral microcirculation is protected during experimental hemorrhagic shock. Crit Care Med 2010, 38:928-932.

29. Ristagno G, Sun S, Tang W, Castillo C, Weil MH: Effects of epinephrine and vasopressin on cerebral microcirculatory flows during and after cardiopulmonary resuscitation. Crit Care Med 2007, 35:2145-2149.

30. Institute of Laboratory Animal Resources and National Research Council. Guide for the Care and Use of Laboratory Animals Washington: National Academy Press 1996.

31. Dubois EF: The estimation of the surface area of the body. Basal Metabolism in Health and Disease Philadelphia: Lea and FebigerDubois EF 1936, 125-144.

32. De Backer D, Hollenberg S, Boerma C, Goedhart P, Büchele G, OspinaTascon G, Dobbe I, Ince C: How to evaluate the microcirculation: report of a round table conference. Crit Care 2007, 11:R101.

33. Su F, Brands R, Wang Z, Verdant C, Bruhn A, Cai Y, Raaben W, Wulferink M, Vincent JL: Beneficial effects of alkaline phosphatase in septic shock. Crit Care Med 2006, 34:2182-2187.

34. Boerma EC, van der Voort PH, Spronk PE, Ince C: Relationship between sublingual and intestinal microcirculatory perfusion in patients with abdominal sepsis. Crit Care Med 2007, 35:1055-1060.

35. Lehr HA, Bittinger F, Kirkpatrick CJ: Microcirculatory dysfunction in sepsis: a pathogenetic basis for therapy? J Pathol 2000, 190:373-386.

36. Bauer P, Lush CW, Kvietys PR, Russell GM, Granger DN: Role of endotoxin in the expression of endothelial selectins after cecal ligation and perforation. Am J Physiol Regul Integr Comp Physiol 2000, 278:R1140-R1147.

37. Cerwinka WH, Cooper D, Krieglstein CF, Ross CR, McCord JM, Granger DN: Superoxide mediates endotoxin-induced platelet-endothelial cell adhesion in intestinal venules. Am J Physiol Heart Circ Physiol 2003, 284: H535-H541.
38. Okamoto H, Ito O, Roman RJ, Hudetz AG: Role of inducible nitric oxide synthase and cyclooxygenase- 2 in endotoxin-induced cerebral hyperemia. Stroke 1998, 29:1209-1218.

39. Wang D, Wei J, Hsu K, Jau J, Lieu MW, Chao TJ, Chen HI: Effects of nitric oxide synthase inhibitors on systemic hypotension, cytokines and inducible nitric oxide synthase expression and lung injury following endotoxin administration in rats. J Biomed Sci 1999, 6:28-35.

40. den Uil CA, Klijn E, Lagrand WK, Brugts JJ, Ince C, Spronk PE, Simoons ML: The microcirculation in health and critical disease. Prog Cardiovasc Dis 2008, 51:161-170.

41. Chierego M, Verdant C, De Backer D: Microcirculatory alterations in critically ill patients. Minerva Anestesiol 2006, 72:199-205.

42. Zonta M, Angulo MC, Gobbo S, Rosengarten B, Hossmann KA, Pozzan T, Carmignoto G: Neuron-to-astrocyte signaling is central to the dynamic control of brain microcirculation. Nat Neurosci 2003, 6:43-50.

43. Panerai RB: Assessment of cerebral pressure autoregulation in humans-a review of measurement methods. Physiol Meas 1998, 19:305-338.

44. Wijdicks EF, Stevens M: The role of hypotension in septic encephalopathy following surgical procedures. Arch Neurol 1992, 49:653-656.

45. Ekstrom-Jodal B, Haggendal E, Larsson LE: Cerebral blood flow and oxygen uptake in endotoxic shock. An experimental study in dogs. Acta Anaesthesiol Scand 1982, 26:163-170.

46. Berre J, De Backer D, Moraine JJ, Vincent JL, Kahn RJ: Effects of dobutamine and prostacyclin on cerebral blood flow velocity in septic patients. J Crit Care 1994, 9:1-6.

47. Berre J, De Backer D, Moraine JJ, Melot C, Kahn RJ, Vincent JL: Dobutamine increases cerebral blood flow velocity and jugular bulb hemoglobin saturation in septic patients. Crit Care Med 1997, 25:392-398.

48. Rosengarten $B$, Hecht M, Wolff S, Kaps M: Autoregulative function in the brain in an endotoxic rat shock model. Inflamm Res 2008, 57:542-546.

49. Esen F, Erdem T, Aktan D, Orhan M, Kaya M, Eraksoy H, Cakar N, Telci L: Effect of magnesium sulfate administration on blood-brain barrier in a rat model of intraperitoneal sepsis: a randomized controlled experimental study. Crit Care 2005, 9:R18-R23.

50. Kamenova M, lakimov I, Ninova I, Nikolov N: Morphological studies of the changes in the cerebral cortex in endotoxic shock in dogs. Eksp Med Morfol 1980, 19:109-115.

51. Kafa IM, Ari I, Kurt MA: The peri-microvascular edema in hippocampal CA1 area in a rat model of sepsis. Neuropathology 2007, 27:213-220.

52. Papadopoulos MC, Lamb FJ, Moss RF, Davies DC, Tighe D, Bennett ED: Faecal peritonitis causes oedema and neuronal injury in pig cerebral cortex. Clin Sci (Lond) 1999, 96:461-466.

53. Rosengarten B, Walberer M, Allendoerfer J, Mueller C, Schwarz N, Bachmann G, Gerriets T: LPS-induced endotoxic shock does not cause early brain edema formation - an MRI study in rats. Inflamm Res 2008 , 57:479-483.

54. Neuroanatomy: Dissection of the sheep brain. [http://bc.barnard.edu/ $\sim$ ktaylor/Neuroanatomy.pdf].

55. Pennings FA, Bouma GJ, Ince C: Direct observation of the human cerebral microcirculation during aneurysm surgery reveals increased arteriolar contractility. Stroke 2004, 35:1284-1288.

doi:10.1186/cc9205

Cite this article as: Taccone et al: Cerebral microcirculation is impaired during sepsis: an experimental study. Critical Care 2010 14:R140.

\section{Submit your next manuscript to BioMed Central and take full advantage of:}

- Convenient online submission

- Thorough peer review

- No space constraints or color figure charges

- Immediate publication on acceptance

- Inclusion in PubMed, CAS, Scopus and Google Scholar

- Research which is freely available for redistribution

Submit your manuscript at www.biomedcentral.com/submit
C Biomed Central 